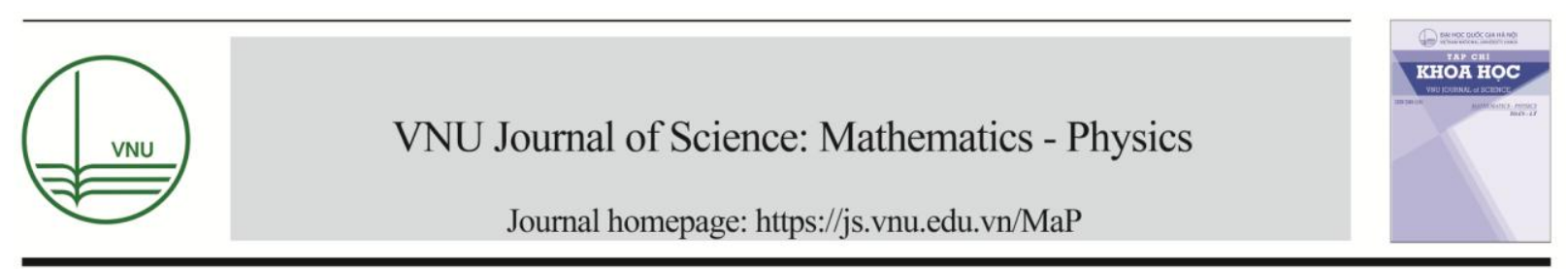

\title{
The Zeta Potential Measurements in Sandpacks Saturated with Monovalent Electrolytes
}

\author{
Luong Duy Thanh* \\ Thuy Loi University, 175 Tay Son, Dong Da, Hanoi, Vietnam \\ Received 16 October 2017 \\ Revised 15 November 2017; Accepted 16 January 2018
}

\begin{abstract}
Measurements of the zeta potential in sandpacks saturated with monovalent electrolytes at six different electrolyte concentrations have been reported. The values we record are classified into two groups based on the magnitude of the zeta potential: group 1 (samples S1 and S2) and group 2 (samples S3 and S4). The measured zeta potential in magnitude in group 1 is much smaller than that in group 2 and in literature at the same electrolyte concentration. The reason for a big variation of the zeta potential between group 1 and group 2 may be due to the difference in technique of making sand particles of different size leading to change of particle surface properties. Consequently, the zeta potential that depends on the surface properties would vary. The results show that there is a gradual decrease in the zeta potential with increase in monovalent electrolyte concentration (from $10^{-4} \mathrm{M}$ to $10^{-2} \mathrm{M}$ ). Additionally, the empirical expressions between the zeta potential and electrolyte concentration are obtained in this work for both group 1 and group 2. The obtained expression for group 2 is in good agreement with those available in literature. From the experimental data in combination with a theoretical model, the binding constants for $\mathrm{Na}^{+}$and $\mathrm{K}^{+}$cations are obtained for the samples of group 2 and they are in the same range reported in literature for silica-based samples.
\end{abstract}

Keywords: Streaming potential, zeta potential, porous media, sands, electrolytes

\section{Introduction}

The streaming potential is induced by the relative motion between the fluid and the solid surface. In porous media such as rocks, sands or soils, the electric current density, linked to the ions within the fluid, is coupled to the fluid flow. Streaming potential plays an important role in geophysical applications. For example, the streaming potential is used to map subsurface flow and detect subsurface flow patterns in oil reservoirs [e.g., 1]. Streaming potential is also used to monitor

\footnotetext{
* Tel.: 84-936946975.

Email: luongduythanh2003@yahoo.com

https//doi.org/ 10.25073/2588-1124/vnumap.4238
} 
subsurface flow in geothermal areas and volcanoes [e.g., 2, 3]. Monitoring of streaming potential anomalies has been proposed as a means of predicting earthquakes [e.g., 4, 5] and detecting of seepage through water retention structures such as dams, dikes, reservoir floors, and canals [6].

The zeta potential is one of the key parameters in streaming potential. The zeta potential of liquidrock systems depends on many parameters such as mineral composition of rocks, fluid properties, temperature etc [7]. At a given porous media, the most influencing parameter is the fluid conductivity. Therefore, it is useful to have an empirical relation between the zeta potential and fluid conductivity or electrolyte concentration. For example, by fitting experimental data for quartz and $\mathrm{NaCI}$ or $\mathrm{KCI}$ at $\mathrm{pH}$ $=7$ and temperature of $25^{\circ} \mathrm{C}$, Pride and Morgan [8] obtain an empirical relation between the zeta potential and electrolyte concentration. Similarly, Vinogradov et al. [9] obtain another relation between the zeta potential and electrolyte concentration based on published zeta potential data for quartz, silica, glass beads, sandstone, Stainton and Fontainebleau in $\mathrm{NaCl}$ at $\mathrm{pH}=6-8$. However, experimental data sets they used for fitting are from different sources with dissimilar fluid conductivity, fluid $\mathrm{pH}$, temperature, mineral composition of porous media. All those dissimilarities may cause the empirical expressions less accurate. To critically seek empirical expressions to estimate the zeta potential from electrolyte concentration, we have carried out zeta potential measurements for a set of four sandpacks (denoted as S1, S2, S3 and S4) saturated by four monovalent electrolytes $(\mathrm{NaCl}$, $\mathrm{NaI}, \mathrm{KCl}$ and $\mathrm{KI})$ at six different electrolyte concentrations $\left(10^{-4} \mathrm{M}, 5.0 \times 10^{-4} \mathrm{M}, 10^{-3} \mathrm{M}, 2.5 \times 10^{-3} \mathrm{M}\right.$, $5.0 \times 10^{-3} \mathrm{M}$, and $\left.10^{-2} \mathrm{M}\right)$.

The measured values of the zeta potential are classified into two groups based on the magnitude: group 1 (samples S1 and S2) and group 2 (samples S3 and S4). The magnitude of the zeta potential in group 1 is much smaller than that in group 2 and in literature at the same electrolyte concentration. The reason for a big variation of the zeta potential between samples may be due to the difference in technique of making sand particles of different size leading to change of particle surface properties. Consequently, the zeta potential that depends on the surface properties would vary. The results also show that there is a decrease in the zeta potential with increase in monovalent electrolyte concentration. Additionally, the empirical expressions between the zeta potential and electrolyte concentration are obtained in this work for both group 1 and group 2. The obtained expression for group 2 is in good agreement with those available in literature. From the experimental data in combination with the theoretical model, the binding constants for $\mathrm{Na}^{+}$and $\mathrm{K}^{+}$cations are obtained for the samples of group 2 and they are in the same range reported in literature for silica-based samples.

\section{Theoretical background of streaming potential}

\subsection{Physical chemistry of the electric double layer}

Streaming potential is the result of a coupling between fluid flow and electric current flow in a porous medium which is formed by mineral solid grains such as silicates, oxides, carbonates. It is directly related to the existence of an electric double layer (EDL) that exists at the solid-liquid interface. Most substances acquire a surface electric charge when brought into contact with aqueous systems. To understand the origin of surface charge, the physical chemistry at a silica surface in the presence of the aqueous fluids is presented. The discussion of the reactions at a silica surface in contact with aqueous fluids has been introduced $[7,10]$. It is stated that there are two types of neutral surface group for silica: doubly coordinated siloxal $>\mathrm{Si}_{2} \mathrm{O}^{0}$ and singly coordinated silanol $>\mathrm{SiOH}^{0}$ (where > refer to the mineral lattice and the superscript " 0 " means no charge). The siloxal group $\left(>\mathrm{Si}_{2} \mathrm{O}^{0}\right)$ can be considered inert. However, the surface silanol group $\left(>\mathrm{SiOH}^{0}\right)$ can react readily to 
produce positive surface sites $\left(>\mathrm{SiOH}_{2}^{+}\right)$at very acid $\mathrm{pH}<\mathrm{pH}_{\mathrm{pzc}}=2-3$ and negative surface sites $\left(>\mathrm{SiO}^{-}\right.$) at $\mathrm{pH}>\mathrm{pH}_{\mathrm{pzc}}$ where $\mathrm{pH}_{\mathrm{pzc}}$ is the $\mathrm{pH}$ at the point of zero charge (at which concentration of $>\mathrm{SiOH}_{2}{ }^{+}$is equal to that of $>\mathrm{SiO}^{-}$). The surface mineral reactions at the silanol surfaces in contact with 1:1 electrolyte solutions with the fluid $\mathrm{pH}$ limited to a range of 6-8 are:

To simplify the problem, silica grains in contact with 1:1 electrolyte solutions (i.e., monovalent electrolytes with one cation and one anion) such as $\mathrm{NaCl}$ is considered with the fluid $\mathrm{pH}$ limited to a range of 6-8. The surface mineral reactions at the silanol surface sites are:

for deprotonation of silanol groups

$>\mathrm{SiOH}^{0} \Leftrightarrow>\mathrm{SiO}^{-}+\mathrm{H}^{+}$,

for cation adsorption on silica surfaces

$>\mathrm{SiOH}^{0}+\mathrm{Me}^{+} \Leftrightarrow>\mathrm{SiOMe}^{0}+\mathrm{H}^{+}$,

where $\mathrm{Me}^{+}$stands for monovalent cations in the solutions such as $\mathrm{Na}^{+}$or $\mathrm{K}^{+}$. Note that the positive surface site $\left(>\mathrm{SiOH}_{2}{ }^{+}\right)$does not exist at the silica-electrolyte interface for $\mathrm{pH}>6$. Therefore, three types of sites are present at the silica surfaces, one negative $\left(>\mathrm{SiO}^{-}\right)$and two neutral ones $\left(>\mathrm{SiOH}^{0}\right.$ and $>\mathrm{SiOMe}^{0}$ ).

The law of mass action at equilibrium is used to calculate the equilibrium constants for those reactions in the following manner

$$
K_{(-)}=\frac{\Gamma_{S i O^{-}}^{0} . \alpha_{H^{+}}^{0}}{\Gamma_{S i O H}^{0}},
$$

and

$$
K_{\mathrm{Me}}=\frac{\Gamma_{\mathrm{SiOMe}}^{0} \cdot \alpha_{H^{+}}^{0}}{\Gamma_{\mathrm{SiOH}}^{0} \cdot \alpha_{\mathrm{Me}^{+}}^{0}},
$$

where $K_{(-)}$is the disassociation constant for deprotonation of silanol surface sites, $K_{M e}$ is the binding constant for cation adsorption on the silica surfaces, $\Gamma_{i}^{0}$ is the surface site density of surface species $i\left(\operatorname{sites} / \mathrm{m}^{2}\right)$ and $\alpha_{i}^{0}$ is the activity of an ionic species $i$ at the closest approach of the mineral surface (no units).

The total surface site density $\left(\Gamma_{S}^{0}\right)$ is

$\Gamma_{S}^{0}=\Gamma_{\text {SiOH }}^{0}+\Gamma_{\text {SiO- }}^{0}+\Gamma_{\text {SiOMe }}^{0}$

Eq. (5) is a conservation equation for mineral surface groups. From Eq. (3), Eq. (4) and Eq. (5), the surface site density of sites $\Gamma_{S i O^{-}}^{0}$ and $\Gamma_{S i O M e}^{0}$ are obtained. The mineral surface charge density $Q_{S}^{0}$ in $\mathrm{C} / \mathrm{m}^{2}$ can be found by summing the surface densities of charged surface groups (only one charged surface group of $\Gamma_{\mathrm{SiO}^{-}}^{0}$ in this problem) as

$$
Q_{S}^{0}=-e . \Gamma_{S i O^{-}}^{0}
$$

where $e$ is the elementary charge.

The mineral surface charge repels ions in the electrolyte whose charges have the same sign as the surface charge (called the "coions") and attracts ions whose charges have the opposite sign (called the "counterions" and normally cations) in the vicinity of the electrolyte-silica interface. This leads to the 
charge distribution known as the electric double layer (EDL) (see Fig. 1). The EDL is made up of the Stern layer, where cations are adsorbed on the surface and are immobile due to the strong electrostatic attraction, and the diffuse layer, where the ions are mobile. The distribution of ions and the electric potential within the diffuse layer is governed by the Poisson-Boltzman (PB) equation which accounts for the balance between electrostatic and thermal diffusional forces [11]. The solution to the linear PB equation in one dimension perpendicular to a broad planar interface is well-known and produces an electric potential profile that decays approximately exponentially with distance as shown in Fig. 1. In the bulk liquid, the number of cations and anions is equal so that it is electrically neutral. The closest plane to the solid surface in the diffuse layer at which flow occurs is termed the shear plane or the slipping plane, and the electrical potential at this plane is called the zeta potential $(\zeta)$ as shown in Fig. 1.

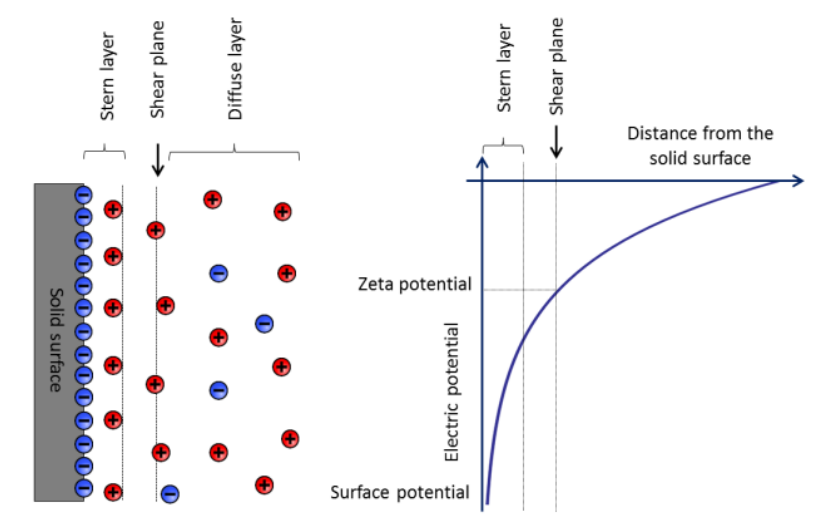

Figure 1. Stern model for the charge and electric potential distribution in the EDL at a solid-liquid interface $[12,13]$.

\subsection{Zeta potential}

According to a theoretical model for the zeta potential that has been well described by $[7,10]$, the electrical potential distribution $\varphi$ in the EDL has, approximately, an exponential distribution as follows:

$$
\varphi=\varphi_{d} \exp \left(-\frac{\chi}{\chi_{d}}\right)
$$

where $\varphi_{d}$ is the Stern potential (V) given by

$$
\varphi_{d}=\frac{2 k_{b} T}{3 e} \ln \left\{\frac{\sqrt{8.10^{3} \varepsilon_{o} \varepsilon_{r} k_{b} T N}\left(10^{-p H}+K_{M e} C_{f}\right)}{2 e \Gamma_{S}^{0} K_{(-)}}\left[\frac{C_{f}+10^{-p H}+10^{p H-p K_{w}}}{\sqrt{C_{f}}}\right]\right\}
$$

and $\chi_{d}$ is the Debye length (m) given by

$$
\chi_{d}=\sqrt{\frac{\varepsilon_{o} \varepsilon_{r} k_{b} T}{2000 N e^{2} C_{f}}}
$$

and $\chi$ is the distance from the mineral surface $(\mathrm{m})$. The zeta potential $(\mathrm{V})$ can then be calculated as 


$$
\zeta=\varphi_{d} \exp \left(-\frac{\chi_{\zeta}}{\chi_{d}}\right)
$$

where $\chi_{\zeta}$ is the shear plane distance - the distance from the mineral surface to the shear plane (m). There is currently no method to evaluate the shear plane distance. In the work reported by [7], the shear plane distance was taken as $2.4 \times 10^{-10} \mathrm{~m}$ to compare the theoretical model with experimental datasets of 17 different solid-fluid combinations. It was shown that the theoretical model fits the experimental data well. Therefore, the shear plane distance $\left(\chi_{\zeta}\right)$ is taken as $2.4 \times 10^{-10} \mathrm{~m}$ in this work for modeling.

In Eq. (8) and Eq. (9), $k_{b}$ is the Boltzmann's constant $\left(1.38 \times 10^{-23} \mathrm{~J} / \mathrm{K}[14]\right), \varepsilon_{0}$ is the dielectric permittivity in vacuum $\left(8.854 \times 10^{-12} \mathrm{~F} / \mathrm{m}\right.$ [14] $), \varepsilon_{r}$ is the relative permittivity (no units), $T$ is temperature (in $\mathrm{K}), e$ is the elementary charge $\left(1.602 \times 10^{-19} \mathrm{C}[14]\right), N$ is the Avogadro's number $\left(6.022 \times 10^{23} / \mathrm{mol}[14]\right), C_{f}$ is the electrolyte concentration $(\mathrm{mol} / \mathrm{L}), p H$ is the fluid $\mathrm{pH}, K_{\mathrm{Me}}$ is the binding constant for cation adsorption (no units), $K_{(-)}$is the disassociation constant for dehydrogenization of silanol surface sites (no units), $\Gamma_{S}^{0}$ is the surface site density (sites $/ \mathrm{m}^{2}$ ) and $K_{w}$ is the disassociation constant of water (no units).

\subsection{Streaming potential}

In a porous medium the electric current density and the fluid flux are coupled, so that the streaming potential is generated by fluids moving through porous media. The parameter that quantifies this coupling is the streaming potential coefficient (SPC) and is defined as

$$
C_{S}=\frac{\Delta V}{\Delta P}=\frac{\varepsilon_{r} \varepsilon_{o} \zeta}{\eta \sigma_{e f f}},
$$

where $\Delta V$ is the measured streaming potential $(\mathrm{V}), \Delta P$ is the applied pressure difference $(\mathrm{Pa}), \eta$ is the dynamic viscosity of the fluid (Pa.s), $\sigma_{\text {eff }}$ is the effective conductivity $(\mathrm{S} / \mathrm{m})$, and $\zeta$ is the zeta potential (V). The effective conductivity includes the fluid conductivity and the surface conductivity. The SPC can also be written as ([15] and reference therein)

$$
C_{S}=\frac{\varepsilon_{r} \varepsilon_{o} \zeta}{\eta F \sigma_{r}}
$$

where $\sigma_{r}(\mathrm{~S} / \mathrm{m})$ is the electrical conductivity of the sample saturated by a fluid with a conductivity of $\sigma_{f}(\mathrm{~S} / \mathrm{m})$ and $F$ is the formation factor (no units).

\section{Experiment}

Samples and electrolytes used in this work are the same as ones that have been already reported in [15]. The samples are four unconsolidated samples of sand particles with different diameters denoted as S1, S2, S3 and S4 (See Table 1). The samples are made up of blasting sand particles obtained from Unicorn ICS BV Company. Four monovalent electrolytes ( $\mathrm{NaCl}, \mathrm{NaI}, \mathrm{KCl}$ and $\mathrm{KI})$ are used with 6 different concentrations $\left(10^{-4} \mathrm{M}, 5.0 \times 10^{-4} \mathrm{M}, 10^{-3} \mathrm{M}, 2.5 \times 10^{-3} \mathrm{M}, 5.0 \times 10^{-3} \mathrm{M}\right.$, and $\left.10^{-2} \mathrm{M}\right)$. All measurements are carried out at room temperature $\left(22 \pm 1^{\circ} \mathrm{C}\right)$. 


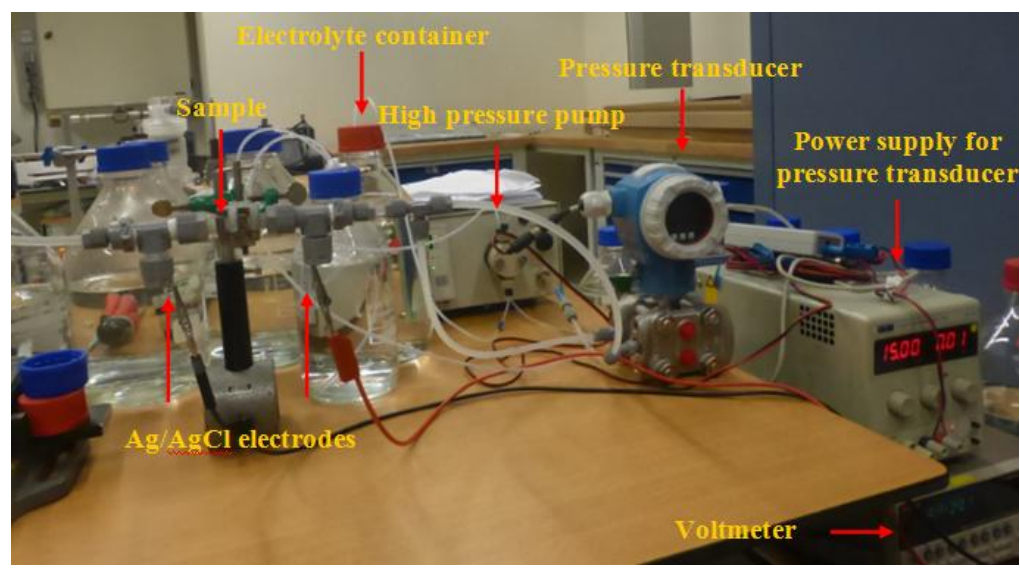

Figure 2. Experimental setup for streaming potential measurements.

The experimental setup and the way used to collect the SPC is similar to that described in [15] and re-shown in Fig. 2. The values of the SPC for all samples at different electrolyte concentrations are already reported in [15] and re-shown in Table 1 except for two samples S1 and S2 at electrolyte concentration of $10^{-2} \mathrm{M}$. Because these samples are very permeable, they need a very large flow rate to generate measurable electric potentials at high electrolyte concentration. It is found that the SPC is negative for all samples and all electrolytes.

The electrical conductivity of the samples saturated by electrolytes $\left(\sigma_{r}\right)$ is obtained from the resistance measured by an impedance analyzer (Hioki IM3570) with the knowledge of the geometry of the sample (the length, the diameter). In order to measure the resistance of saturated samples, two silver meshes acting as two electrodes are used. The electrodes are placed on both sides against the sample. Based on the measured SPC, the measured electrical conductivity of the samples $\left(\sigma_{r}\right)$, formation factors that are measured and re-shown in Table 1, the viscosity and dielectric constant of water, the zeta potential is deduced from equation 2 . The zeta potential at different electrolyte concentrations is reported in Table 2. The maximum error of measured zeta potential is $12 \%$. The result shows that for a given sample the zeta potential in magnitude increase with decreasing electrolyte concentration for all electrolytes. The observation is in good agreement literature [e.g., 7, 16].

Table 1. The streaming potential coefficient ( $\mathrm{mV} / \mathrm{bar})$ for different electrolyte concentrations and the formation factor of the samples $F$ already reported in [15]

\begin{tabular}{llllllllll}
\hline Sample & Size $(\mu \mathrm{m})$ & $F$ & Electrolyte & $10^{-4} \mathrm{M}$ & $5 \times 10^{-4} \mathrm{M}$ & $10^{-3} \mathrm{M}$ & $2.5 \times 10^{-3} \mathrm{M}$ & $5 \times 10^{-3} \mathrm{M}$ & $10^{-2} \mathrm{M}$ \\
\hline \multirow{3}{*}{ S1 } & & & $\mathrm{NaCl}$ & -1250 & -202 & -120 & -41 & -20 & \\
& \multirow{3}{*}{$300-400$} & & $\mathrm{NaI}$ & -1275 & -206 & -125 & -44 & -22 & \\
& & $\mathrm{KCl}$ & -1033 & -183 & -91 & -30 & -11 & \\
& & $\mathrm{KI}$ & -1233 & -200 & -118 & -38 & -19 & \\
& & & $\mathrm{NaCl}$ & -1950 & -380 & -179 & -70 & -32 & \\
S2 & \multirow{3}{*}{$200-300$} & & $\mathrm{NaI}$ & -2067 & -403 & -185 & -87 & -35 & \\
& & $\mathrm{KCl}$ & -1230 & -263 & -127 & -58 & -26 & \\
& & & $\mathrm{KI}$ & -1700 & -350 & -170 & -60 & -27 & \\
& & & & & & & & &
\end{tabular}




\begin{tabular}{|c|c|c|c|c|c|c|c|c|c|}
\hline \multirow{3}{*}{ S3 } & & & $\mathrm{NaCl}$ & -2100 & -625 & -357 & -145 & -63 & -31 \\
\hline & \multirow[b]{2}{*}{$90-150$} & \multirow[t]{2}{*}{4.2} & $\mathrm{NaI}$ & -2466 & -763 & -400 & -160 & -77 & -34 \\
\hline & & & $\mathrm{KCl}$ & -1567 & -570 & -313 & -120 & -65 & -25 \\
\hline \multirow{5}{*}{ S4 } & & & KI & -1665 & -573 & -330 & -123 & -58 & -26 \\
\hline & \multirow{4}{*}{$0-50$} & \multirow{4}{*}{4.3} & $\mathrm{NaCl}$ & -4021 & -842 & -429 & -149 & -69 & -33 \\
\hline & & & $\mathrm{NaI}$ & -4067 & -850 & -435 & -151 & -81 & -36 \\
\hline & & & $\mathrm{KCl}$ & -2333 & -576 & -290 & -106 & -71 & -29 \\
\hline & & & KI & -3933 & -836 & -430 & -147 & -75 & -31 \\
\hline
\end{tabular}

\section{Results and discussion}

From Table 2, the dependence of the zeta potential on types of electrolyte is shown in Fig. 3 for a representative sample (for example, sample S3). Fig. 3 shows that the magnitude of the zeta potential decreases with increasing electrolyte concentration for all electrolytes as reported in literature [e.g., 7, 16]. This behavior is similar to other samples. As stated in [15], it is seen that that the zeta potential mostly depend on types of cation in electrolytes. This can be qualitatively explained by the difference in the binding constant of cations. For example, the binding constant of $\mathrm{K}^{+}$is larger than $\mathrm{Na}^{+}$[7]. Therefore, at the same ionic strength more cations of $\mathrm{K}^{+}$are absorbed on the negative solid surface than cations of $\mathrm{Na}^{+}$. This makes the electric potential on the shear plane (the zeta potential) smaller in the electrolyte containing cations of $\mathrm{K}^{+}$than that in the electrolyte containing cations of $\mathrm{Na}^{+}$.

Table 2. Zeta potential for four monovalent electrolytes at different concentrations

\begin{tabular}{llllllll}
\hline Sample & Electrolyte & $10^{-4} \mathrm{M}$ & $5 \times 10^{-4} \mathrm{M}$ & $10^{-3} \mathrm{M}$ & $2.5 \times 10^{-3} \mathrm{M}$ & $5 \times 10^{-3} \mathrm{M}$ & $10^{-2} \mathrm{M}$ \\
\hline \multirow{3}{*}{$\mathrm{S} 1$} & $\mathrm{NaCl}$ & -23 & -19 & -16 & -16 & -14 & \\
& $\mathrm{NaI}$ & -24 & -20 & -19 & -18 & -16 & \\
& $\mathrm{KCl}$ & -16 & -15 & -16 & -13 & -9 & \\
& $\mathrm{KI}$ & -19 & -16 & -17 & -13 & -12 & \\
\hline \multirow{3}{*}{$\mathrm{S} 2$} & $\mathrm{NaCl}$ & -22 & -19 & -18 & -18 & -14 & \\
& $\mathrm{NaI}$ & -23 & -20 & -19 & -19 & -16 & \\
& $\mathrm{KCl}$ & -17 & -16 & -16 & -13 & -10 & \\
& $\mathrm{KI}$ & -21 & -17 & -17 & -13 & -12 & \\
\hline \multirow{3}{*}{$\mathrm{S} 3$} & $\mathrm{NaCl}$ & -86 & -80 & -78 & -73 & -64 & -47 \\
& $\mathrm{NaI}$ & -96 & -91 & -86 & -70 & -66 & -48 \\
& $\mathrm{KCl}$ & -55 & -57 & -54 & -50 & -40 & -24 \\
& $\mathrm{KI}$ & -68 & -63 & -59 & -52 & -51 & -33 \\
\hline \multirow{3}{*}{$\mathrm{S} 4$} & $\mathrm{NaCl}$ & -77 & -73 & -70 & -56 & -52 & -48 \\
& $\mathrm{NaI}$ & -80 & -78 & -74 & -59 & -64 & -55 \\
& $\mathrm{KCl}$ & -56 & -55 & -52 & -51 & -48 & -41 \\
& $\mathrm{KI}$ & -71 & -68 & -64 & -58 & -57 & -46 \\
\hline
\end{tabular}




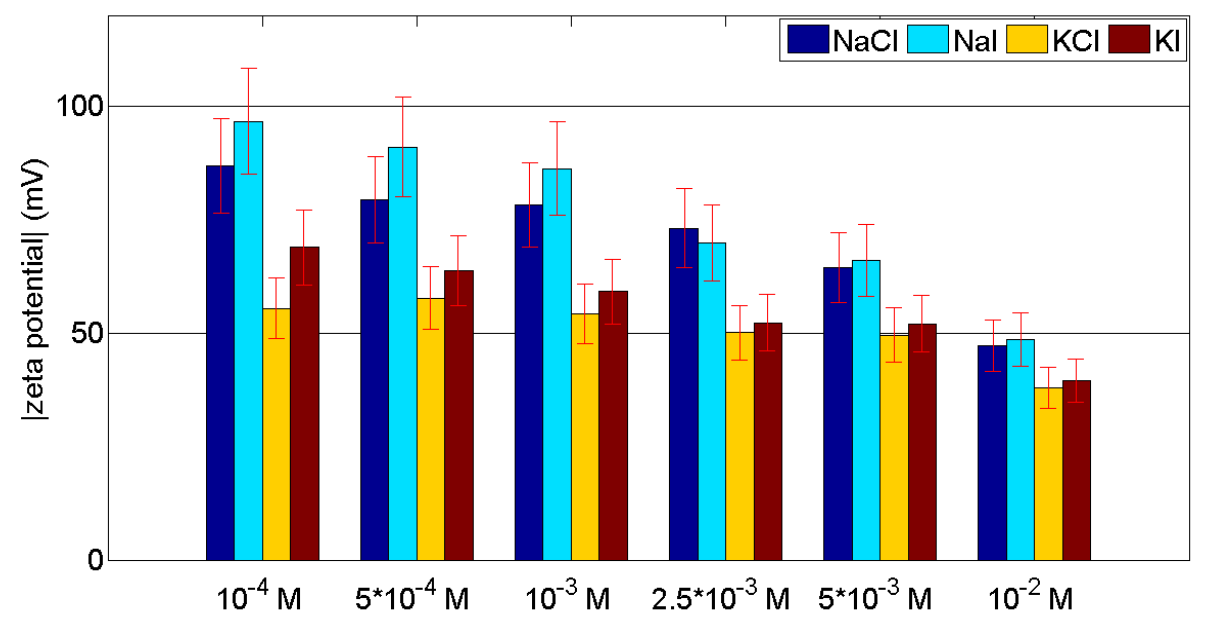

Figure 3. The variation of the zeta potential in magnitude with electrolyte concentration for different electrolytes and for the sample S3.

Fig. 4 shows the variation of the zeta potential with samples for electrolyte NaI, for example. It is seen that at a given electrolyte concentration, the samples can be classified into two groups based on the magnitude of the zeta potential: group 1 (larger sand particle group) includes samples S1 and S2 and group 2 (smaller sand particle group) includes samples S3 and S4. This can be explained by the difference in technique used to produce sand particles leading to the change of particle surface properties.

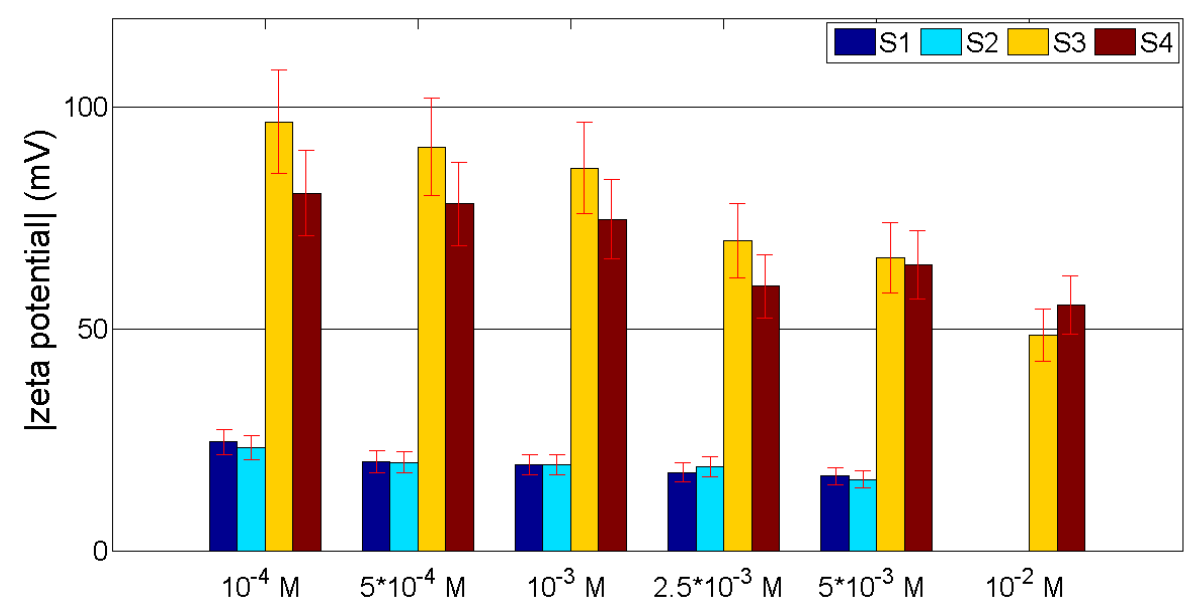

Figure 4. The magnitude of the zeta potential as a function of electrolyte concentration for different samples saturated by electrolyte $\mathrm{NaI}$.

The variation of the zeta potential of group 1 and group 2 with monovalent electrolyte concentration is shown by a lower part and upper part in Fig. 5, respectively. By fitting the 
experimental data of the group 1 (the red solid line in Fig.5), the empirical relation between the zeta potential and electrolyte concentration for the group 1 is obtained as

$$
\zeta=-0.63+5.2 \log 10\left(C_{f}\right)
$$

and the empirical relation the group 2 (the black solid line in Fig. 5) is obtained as

$$
\zeta=-27+12 \log 10\left(C_{f}\right),
$$

where $\zeta$ is in $\mathrm{mV}$ and $C_{f}$ is the electrolyte concentration (in mole/lit).

Expressions in Eq. (13) and Eq. (14) are similar to ones available in literature. For example, by fitting experimental data for quartz and $\mathrm{NaCI}$ and $\mathrm{KCI}$ at $\mathrm{pH}=7$ and temperature of $25^{\circ} \mathrm{C}$, Pride and Morgan [8] obtain the empirical relation between the zeta potential and electrolyte concentration as

$$
\zeta=8+26 \log 10\left(C_{f}\right)
$$

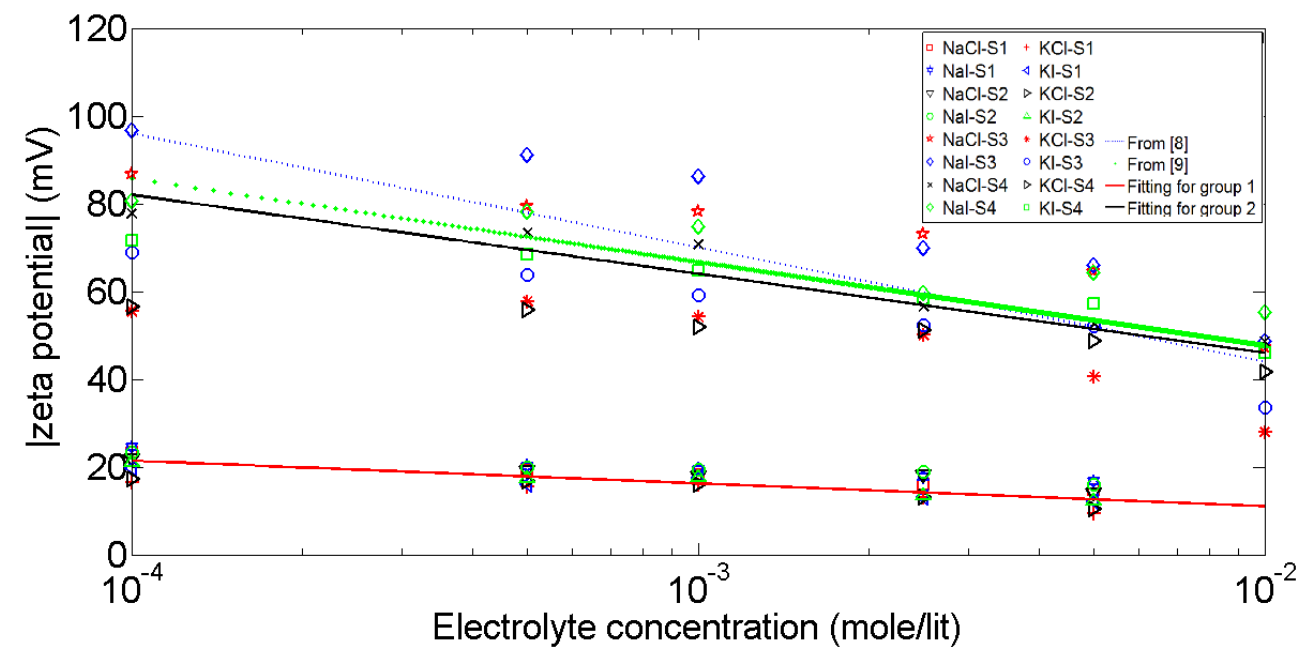

Figure 5. Zeta potential in magnitude as a function of electrolyte concentration for group 1 (lower part) and group 2 (upper part) and different electrolytes ( $\mathrm{NaCl}, \mathrm{NaI}, \mathrm{KCl}$ and $\mathrm{KI}$ ). Symbols are experimental data. The solid lines are the fitting ones. The dashed lines are predicted from $[8,9]$.

Vinogradov et al. [9] obtain the another relation between the zeta potential and electrolyte concentration based on published zeta potential data for quartz, silica, glass beads, sandstone, Stainton and Fontainebleau in $\mathrm{NaCl}$ at $\mathrm{pH}=6-8$ as

$$
\zeta=-9.67+19.02 \log 10\left(C_{f}\right)
$$

The prediction of zeta potential as a function of electrolyte concentration from the empirical expressions of $[8,9]$ is also shown in Fig. 5 (see the upper dashed lines). It is seen that the empirical expressions obtained $[8,9]$ can predict the variation of the measured zeta potential with electrolyte concentration for group 1. The reason for the deviation between the empirical expressions may be due to dissimilarities of fluid conductivity, fluid $\mathrm{pH}$, mineral composition of porous media, temperature etc.

To quantitatively explain the experimental data measured in this work by the theoretical model introduced in section 2, the input parameters given in [7] for silica-based samples are used. The value of the disassociation constant, $K_{(-)}$for dehydrogenization of silanol surface sites is taken as $10^{-7.1}$. The 
shear plane distance, $\chi_{\zeta}$ is taken as $2.4 \times 10^{-10} \mathrm{~m}$. The surface site density $\Gamma_{S}^{0}$ is taken as $5 \times 10^{18}$ site $/ \mathrm{m}^{2}$. The disassociation constant of water, $K_{w}$, at $22^{\circ} \mathrm{C}$ is $9.22 \times 10^{-15}$. The fluid $\mathrm{pH}$ is taken as 6.5 . The binding constant for cation adsorption on silica varies according to which are the dominant cations in the electrolyte and it is not well known. For example, $K_{\mathrm{Me}}\left(\mathrm{Na}^{+}\right)=10^{-3.25}$ and $K_{\mathrm{Me}}\left(\mathrm{K}^{+}\right)=$ $10^{-2.8}$ given by [7]; $K_{\mathrm{Me}}\left(\mathrm{Li}^{+}\right)=10^{-7.8}$ and $K_{\mathrm{Me}}\left(\mathrm{Na}^{+}\right)=10^{-7.1}$ for silica given by [17]; $K_{\mathrm{Me}}\left(\mathrm{Li}^{+}\right)=10^{-7.7}$, $K_{\mathrm{Me}}\left(\mathrm{Na}^{+}\right)=10^{-7.5}$ and $K_{\mathrm{Me}}\left(\mathrm{Cs}_{+}\right)=10^{-7.2}$ given by [18].

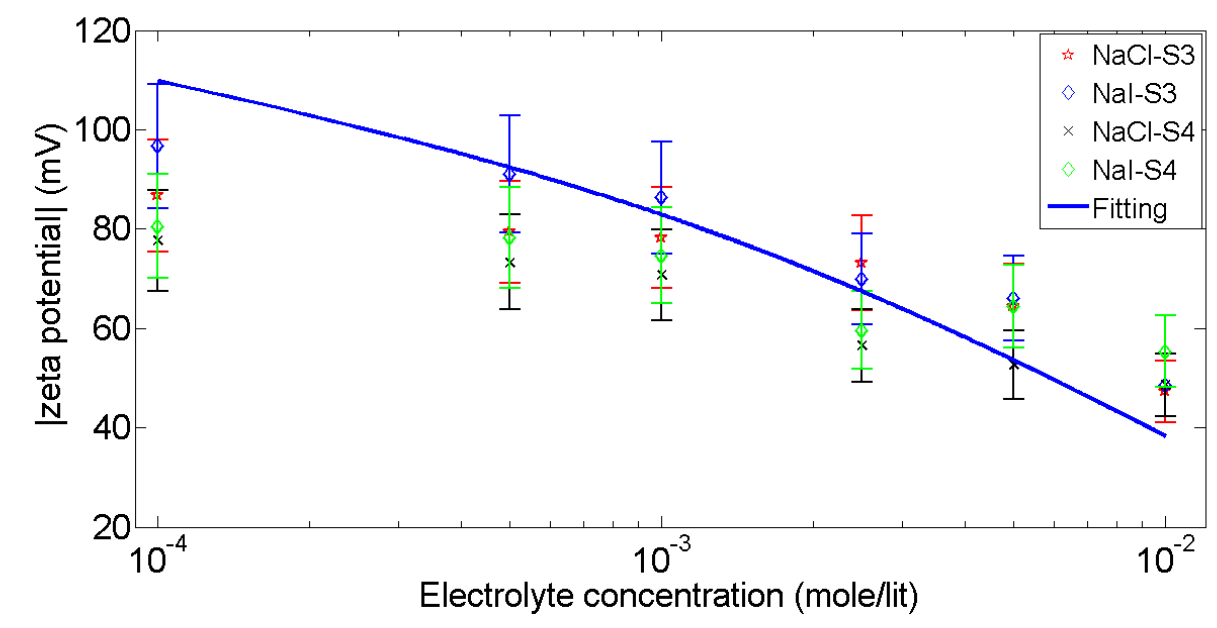

Figure 6. Zeta potential in magnitude as a function of electrolyte concentration for group 2 (samples S3 and S4) for electrolytes containing $\mathrm{Na}^{+}$cations $(\mathrm{NaCl}, \mathrm{NaI})$. Symbols are experimental data. The solid line is the fitting one predicted from the theoretical model in [7].

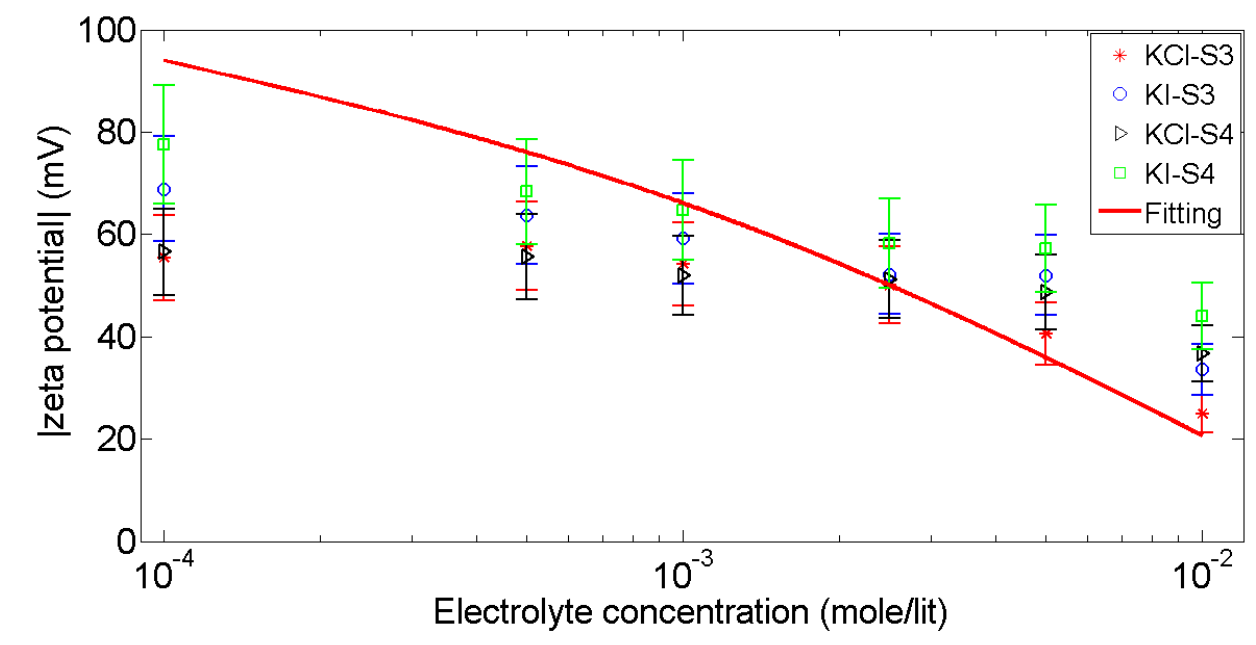

Figure 7. Zeta potential in magnitude as a function of electrolyte concentration for group 2 (samples $\mathrm{S} 3$ and $\mathrm{S} 4$ ) for electrolytes containing $\mathrm{K}^{+}$cations $(\mathrm{KCl}, \mathrm{KI})$. Symbols are experimental data. The solid line is the fitting one predicted from the theoretical model in [7]. 
By fitting the experimental data of the measured zeta potential (see Fig. 6 for electrolytes containing $\mathrm{Na}^{+}$cations and Fig. 7 for electrolytes containing $\mathrm{K}^{+}$cations), the binding constants for cations are obtained as $K_{\mathrm{Me}}\left(\mathrm{Na}^{+}\right)=10^{-4.0}, K_{\mathrm{Me}}\left(\mathrm{K}^{+}\right)=10^{-3.5}$ for the samples of group 2 and they are in the same range reported in literature for silica-based samples. It should be noted that we only use the experimental data of group 2 for fitting because the measured zeta potential of group 1 is far from those available in literature as shown in Fig. 5.

\section{Conclusions}

Measurements of the zeta potential in unconsolidated samples saturated with monovalent electrolytes $(\mathrm{NaCl}, \mathrm{NaI}, \mathrm{KCl}$ and $\mathrm{KI})$ at six different electrolyte concentrations have been reported. The values we recorded are classified into two groups based on the magnitude: group 1 (samples S1 and S2) and group 2 (samples S3 and S4). The measured zeta potential in magnitude in group 1 is much smaller than that in group 2 and in literature at the same electrolyte concentration (about three times smaller). The reason for a big variation of the zeta potential between samples may be due to the difference in technique of making sand particles of different size leading to change of particle surface properties. Consequently, the zeta potential that depends on the surface properties would vary. The results show that there is a gradual decrease in the zeta potential with increase in monovalent electrolyte concentration (from $10^{-4} \mathrm{M}$ to $10^{-2} \mathrm{M}$ ). For any sample, the zeta potential in magnitude is larger in the electrolyte containing cations of $\mathrm{Na}^{+}$than that in the electrolyte containing cations of $\mathrm{K}^{+}$. This is qualitatively explained by the difference in the binding constant for cation adsorption on the silica surfaces. Additionally, the empirical expressions between the zeta potential and electrolyte concentration are obtained in this work for both group 1 and group 2. The obtained expression for group 2 is quite suitable with those available in literature. From the experimental data in combination with the theoretical model, the binding constants for $\mathrm{Na}^{+}$and $\mathrm{K}^{+}$cations are also obtained for the samples of group 2 and they are in the range reported in literature for silica-based samples.

\section{Acknowledgments}

This research is funded by Vietnam National Foundation for Science and Technology Development (NAFOSTED) under grant number 103.99-2016.29. Additionally, the author would like to thank Dr. Rudolf Sprik for granting a three month visit at University of Amsterdam and for his helpful comments and suggestions.

\section{References}

[1] B. Wurmstich, F. D. Morgan, Geophysics 59 (1994) 46-56.

[2] R. F. Corwin, D. B. Hoovert, Geophysics 44 (1979) 226-245.

[3] F. D. Morgan, E. R. Williams, T. R. Madden, Journal of Geophysical Research 94 (1989) 12.449-12.461.

[4] H. Mizutani, T. Ishido, T. Yokokura, S. Ohnishi, Geophys. Res. Lett. 3 (1976).

[5] M. Trique, P. Richon, F. Perrier, J. P. Avouac, J. C. Sabroux, Nature (1999) 137-141.

[6] A. A. Ogilvy, M. A. Ayed, V. A. Bogoslovsky, Geophysical Prospecting 17 (1969) 36-62.

[7] P. W. J. Glover, E. Walker, and M. D. Jackson, Geophysics 77 (2012) D17-D43.

[8] S. R. Pride and F. D. Morgan, Geophysics 56 (1991) 914-925. 
[9] Vinogradov, J., M. Z. Jaafar, and M. D. Jackson, Journal of Geophysical Research Atmospheres 115 (2010) B12204.

[10] O. Stern, Z. Elektrochem 30 (1924) 508-516.

[11] T. Ishido, H. Mizutani, Journal of Geophysical Research 86 (1981) 1763- 1775.

[12] H. M. Jacob, B. Subirm, Electrokinetic and Colloid Transport Phenomena, Wiley-Interscience, 2006.

[13] Revil A. and P. W. J. Glover, Physical Review B 55 (1997) 1757-1773.

[14] Lide, D.R., 2009, Handbook of chemistry and physics, $90^{\text {th }}$ ed., CRC Press.

[15] Luong Duy Thanh, Rudolf Sprik, VNU Journal of Science: Mathematics - Physics, (2017) streaming potential coefficient in unconsolidated samples saturated with monovalent electrolytes (accepted).

[16] B. J. Kirby, E. J. Hasselbrink, Electrophoresis 25 (2004) 187-202.

[17] Dove, P. M., and J. D. Rimstidt, Reviews in Mineralogy and Geochemistry 29 (1994) 259-308.

[18] Kosmulski, M., and D. Dahlsten, Colloids and Surfaces, A: Physicocemical and Engineering Aspects 291 (2006) 212-218. 